\title{
Una monografía de Manuel Martín Salazar sobre la tuberculosis (Cádiz, 1887)
}

A monograph of Manuel Martín Salazar on tuberculosis (Cadiz, 1887)

\section{Uma monografia de Manuel Martín Salazar sobre a tuberculose (Cadiz, 1887)}

\author{
Francisco Herrera-Rodríguez \\ Facultad de Enfermería y Fisioterapia (Universidad de Cádiz)
}

Cómo citar este artículo en edición digital: Herrera-Rodríguez, F. (2017). Una monografía de Manuel Martín Salazar sobre la tuberculosis (Cádiz, 1887). Cultura de los Cuidados (Edición digital), 21(47).

Recuperado de http://dx.doi.org/10.14198/cuid.2017.47.06

Correspondencia: Francisco Herrera-Rodríguez. Facultad de Enfermería y Fisioterapia. Avda. Ana de Viya, 52. 11009-Cádiz. Correo electrónico: francisco.herrera@uca.es

Recibido: 18/07/2016; Aceptado: 11/12/2016

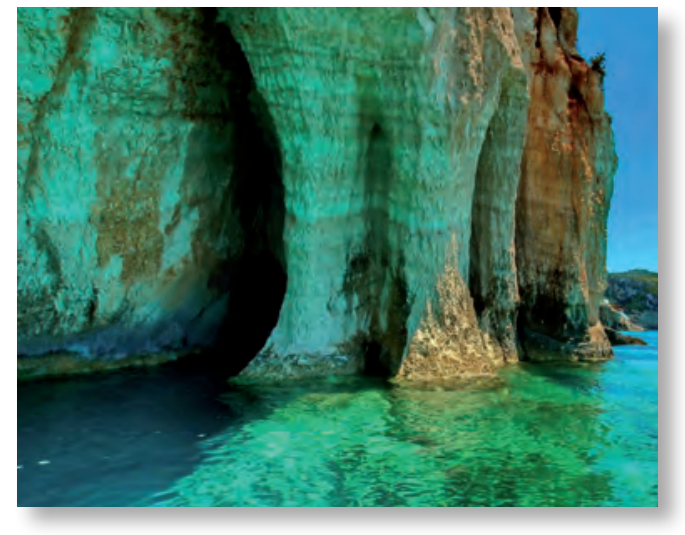

ABSTRACT

In the present article we study the monograph on tuberculosis by Manuel Martín Salazar published in Cadiz in 1887. Besides the prologue which was written by Benito Alcina Rancé, the mentioned monograph presents specific sections on the etiology of tuberculosis infection, heredity, vaccination, disinfection, food and climate, as well as sections dedicated to social hygiene and tuberculosis in the army. This study of Martin Salazar has not received the attention it deserves, especially considering the high incidence of the disease in the Spain of the "Restoration" and that the preventive proposals were made considering the discovery of the tuberculosis bacillus by Robert Koch.

Keywords: Tuberculosis, History of Tuberculosis, tuberculosis, Public Hygiene, nineteenth century, "Restoration", Spain, Cadiz, Manuel Martín Salazar, Benito Alcina Rancé.

\section{RESUMO}

Monografia deste artigo Manuel Martín Salazar sobre a tuberculose, publicado em Cadiz, em 1887, é estudado; além do prólogo de Benito Alcina Rancé, este trabalho apresenta secções específicas sobre a etiologia da infecção por tuberculose, a hereditariedade, a vacinação, desinfecção, comida e clima, bem como seções dedicadas à higiene social e tuberculose no exército. Esta obra de Martin Salazar não recebeu a atenção que merece, especialmente considerando a alta incidência da doença em Espanha da "Restauração" e propostas natureza preventiva são feitas tendo em conta a descoberta do bacilo tuberculose por Robert Koch.

Palavras-chave: Tuberculose, história de tuberculose, a Higiene Pública, do século XIX, “Restauração", Espanha, Cádiz, Manuel Martín Salazar, Benito Alcina Rancé. 


\section{RESUMEN}

En este artículo se estudia la monografía de Manuel Martín Salazar sobre la tuberculosis, publicada en Cádiz, en 1887; además del prólogo de Benito Alcina Rancé, esta obra presenta apartados específicos sobre la etiología de la tuberculosis, el contagio, la herencia, la vacunación, la desinfección, la alimentación y el clima, así como epígrafes dedicados a la higiene social y a la tuberculosis en el ejército. Esta obra de Martín Salazar no ha recibido la atención que se merece, sobre todo teniendo en cuenta la alta incidencia de la enfermedad en la España de la Restauración y que las propuestas de carácter preventivo planteadas se hacen teniendo en cuenta el descubrimiento del bacilo de la tuberculosis por Robert Koch.

Palabras clave: Tuberculosis, Historia de la Tuberculosis, Higiene Pública, siglo XIX, Restauración, España, Cádiz, Manuel Martín Salazar, Benito Alcina Rancé.

\section{A Francisco Salas Fernández (1952-2008), biógrafo de Manuel Martín Salazar.}

\section{INTRODUCCIÓN}

Manuel Martín Salazar (1854-1936) pertenece a la misma Generación de Santiago Ramón y Cajal (1852-1934), con el que convivió en el seno de la Real Academia Nacional de Medicina. Más concretamente, y siguiendo a Laín, lo podemos adscribir a la Generación de 1880 , junto a otros nombres notables de la medicina española como José Gómez Ocaña (1860-1919), Alejandro San Martín (18471908) o Jaume Ferran i Clúa (1851-1929). La gran virtud de estos y otros médicos de la época fue "la introducción en España de una investigación científica a la vez actual, original $y$ exportable", pero en muchas ocasiones sin otros recursos que su vocación personal, su talento y esfuerzo solitario. En esta Genera- ción se han incluido, entre otros, a figuras de otros campos como Marcelino Menéndez Pelayo (1856-1912) y Leonardo Torres Quevedo (1852-1936) (Laín Entralgo, 1998).

No cabe duda de que Martín Salazar fue una figura notable de la medicina española en el primer tercio del siglo XX, destacó muy especialmente por sus conocimientos higienistas y la aplicación de los mismos a la Sanidad española, tanto en el seno del Ejército como posteriormente en la sociedad civil, ejerciendo los cargos de Inspector general de Sanidad exterior e Inspector general de Sanidad, precisamente en este último cargo tuvo que afrontar la difícil situación que provocó la crisis epidémica de 1918 (figura 1).

No se trata en este artículo de consignar todos sus trabajos, muy numerosos, ya que dejó escritos en la prensa médica y publicó monografías, tratando temas como el tifus exantemático, la fiebre tifoidea, el tracoma, las epidemias, la sanidad en España, etc. (Salas Fernández, 1998). Una de sus preocupaciones constantes, como no podía ser de otra manera, fue la tuberculosis, y a esta cuestión vamos a dedicar las páginas que siguen, a través del estudio de una monografía que publicó en Cádiz, en 1887, que se ha tenido poco en cuenta hasta el momento en los estudios realizados sobre la citada enfermedad (Orozco Acuaviva, 1981a).

Los objetivos que nos planteamos son los siguientes:

$1^{\circ}$. Estudiar la monografía de Manuel Martín Salazar sobre la "higiene de la tisis", publicada en el Cádiz de la Restauración y más concretamente en 1887.

$2^{\circ}$. Relacionar esta monografía con los años que Martín Salazar tuvo destino en Cádiz en el seno del Ejército y su posible vinculación en esos años con el catedrático de Higiene de la Facultad de Medicina Benito Alcina Rancé. 
$3^{\circ}$. Comparar sus ideas etiológicas y preventivas con las de otros autores que versaron también sobre la tuberculosis, principalmente con algunos miembros de la escuela médica gaditana de los años ochenta.

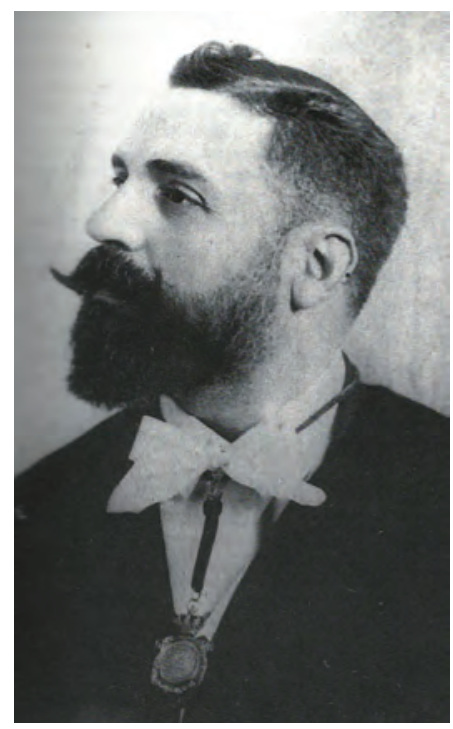

Figura 1: Manuel Martín Salazar (1854-1936). Fuente: Salas Fernández, 1998.

\section{APUNTE BIOGRÁFICO: DESDE SU NA- CIMIENTO HASTA LA DÉCADA DE LOS OCHENTA}

Manuel Martín Salazar nace en Montellano (Sevilla), en octubre de 1854, año en el que se produjo el "Manifiesto de Manzanares", de corte liberal, inaugurándose así el llamado "bienio progresista" (1854-1856) (Tamames, 1985); en ese mismo año apareció en escena una epidemia de cólera (Salas Fernández, 1998). La vida de nuestro biografiado fue larga, falleció con 82 años, en el fatídico 1936 en que dio comienzo la Guerra Civil.

Con aproximadamente 15 años de edad ingresó en el Instituto Provincial de Segunda Enseñanza de Sevilla; en esta localidad y en la de Osuna cursó el Bachillerato. En octubre de 1873 comenzó el primer curso de la carrera en la Escuela de Medicina y Cirugía de Sevilla, aunque posteriormente se trasladó a la Facultad de Medicina de Granada; en el curso 1876-77, Martín Salazar vivió la experiencia dramática de una epidemia de tifus exantemático que acabó con la vida de un íntimo amigo, de varias Hijas de la Caridad, y del catedrático de Clínica médica don Basilio Sanz. En 1878 obtuvo el título de licenciado en medicina $\mathrm{y}$ cirugía e inmediatamente en 1879 ingresó en el Cuerpo de Sanidad Militar, institución en la que realizó una importante labor antes de ocupar puestos de alta responsabilidad en la administración sanitaria civil (Salas Fernández, 1998).

Sobre esta etapa de su vida hemos considerado necesario consultar su hoja de servicios (figura 2), que nos proporciona alguna información de interés que lo vincula a Cádiz y más concretamente al Hospital Militar de esta ciudad.

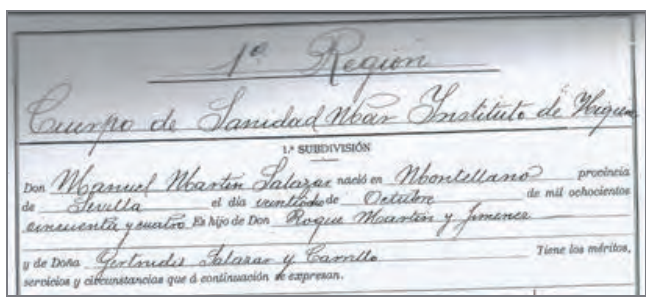

Figura 2: Detalle de la Hoja de Servicio de Manuel Martín Salazar en el Cuerpo de Sanidad Militar. Fuente: Archivo General Militar de Segovia (AGMS).

En agosto de 1879 consta como "Oficial Médico Alumno", pero ya en julio de 1880 figura como "Médico segundo por oposición", puesto que desempañará durante más de 13 años hasta que pasa a ocupar plaza de "Médico $1^{\circ}$ por antigüedad" en 1893 y en 1898 la de "Médico Mayor por antigüedad". En noviembre de 1912 es ascendido al puesto de 
"Subinspector Médico de $2^{a}$ clase de Sanidad Militar por antigüedad”. Como apuntamos en el título de este apartado no debemos extendernos más allá de la década de los ochenta en la biografía de Manuel Martín Salazar, aunque el citado expediente nos ofrece información detallada de su vida profesional y de los destinos que ocupó en el Ejército. Tan solo subrayaremos aquí que tuvo destino en la Academia de Sanidad Militar desde agosto de 1879 hasta julio de 1880, pasando luego hasta el mes de septiembre al Primer Batallón del Regimiento de Infantería de Bailén. Y sobre todo, lo que más nos interesa destacar, estuvo destinado durante seis años en el Hospital Militar de Cádiz, entre 1880 y 1886; hasta el año 1894 encontramos que tuvo destinos en Cádiz o en otros puntos de la provincia, aunque también pasó por Sevilla, Huelva, Madrid y en Melilla para operaciones de campaña; en 1896 embarcó en Cádiz con destino a La Habana (Expediente AGMS).

Llevó a cabo en 1885 una intensa actividad como médico durante la epidemia de cólera, lo que le hizo entrar nuevamente en contacto con las enfermedades infecciosas y las epidemias, recuérdese que en su periodo de estudiante ya vivió en Granada una experiencia al respecto pero con el tifus exantemático (Salas Fernández, 1998). Según apunta este autor, después de un breve destino en Mahón, que está consignado en su expediente militar, regresó nuevamente a Cádiz, incorporándose en el Primer Batallón del Regimiento de Infantería de Álava $n^{\circ}$ 60, destino en el que permaneció hasta 1891. Por tanto, su vinculación con Cádiz queda probada tanto por su biógrafo como por la constancia efectiva en su expediente militar. En 1885 se doctoró, con la calificación de sobresaliente, con una tesis sobre "La locura afectiva desde el punto de vista médico-legal", defendiendo su trabajo ante figuras médicas como Javier Santero, Maestre de San Juan, Alejandro San Martín, Federico Olóriz y Adolfo Moreno Pozo (Salas Fernández, 1998).

No podemos cerrar esta breve reseña biográfica, sin apuntar una circunstancia que hemos podido comprobar en su expediente personal en el Archivo General de la Administración en Alcalá de Henares (Expediente AGA). Y es que nuestro autor, estando como hemos visto en el seno del Cuerpo de Sanidad Militar, tuvo noticia de que se convocaba la cátedra de Higiene de la Facultad de Medicina de Cádiz, presentándose a la misma en octubre de 1889, consiguiendo un meritorio segundo puesto. No se olvide una cuestión, que retomaremos más adelante, y es que esta cátedra de Higiene Privada y Pública en Cádiz la había regentado alguien que creemos fue importante en esos años en la vida profesional de Martín Salazar, nos referimos a Benito Alcina Rancé (1853-1902). También tenemos constancia de que se presentó a la cátedra de Patología General en Granada en 1892, presentando un programa para competir por la misma en la que incluyó una lección, la número 105, que debía versar sobre los "Principios de estadística médica" (figura 3), aspecto que hemos subrayado en otra publicación (Herrera, 1997; Expediente AGA). Estas tentativas a cátedra no fueron fructíferas ya que en su expediente militar observamos que en la década de los noventa tuvo varios destinos que incluyen al menos Cádiz, Melilla, Madrid y La Habana (Expediente AGMS).

Pero sobre la cuestión apuntada de la estadística médica, debemos recordar que Martín Salazar estaba en sintonía con autores como Rudolf Virchow que valoraba la importancia de la estadística como herramienta para conocer 
los trastornos producidos por la organización social y política, y la repercusión en la salud de los ciudadanos (Rosen, 1984), y el cirujano Federico Rubio y Galí, que en 1878, señaló también la necesidad de utilizar las operaciones que brinda la estadística para el progreso de la Higiene (Herrera, 2002); todo esto sin olvidar que Mateo Seoane fue promotor en España de la misma con su obra "Consideraciones generales sobre la estadística médica" (1838) (López Piñero, 1984 y 1990). En esta línea del uso de la estadística médica deben ser consignados los estudios realizados por Rodríguez Ocaña (1985, 1988a, 1988b, 1993, 1996a, 1996b) y Bernabeu Mestre (2007). Volveremos a insistir en este punto en el siguiente apartado.

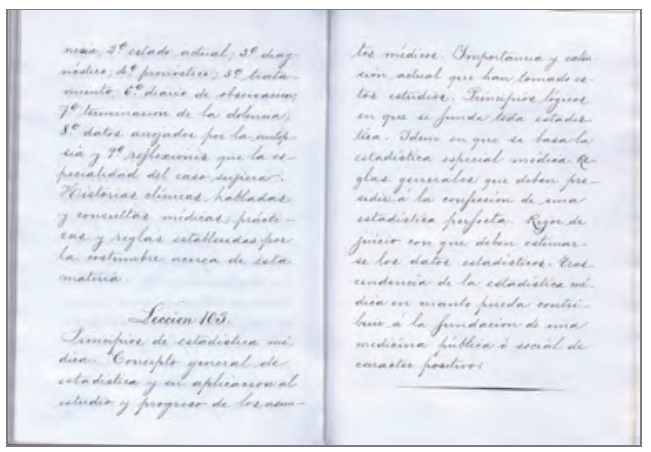

Figura 3: Página manuscrita por Martín Salazar en la que se reflejan los epígrafes de la lección 105 dedicada a los principios de la estadística médica (1892).Fuente: Archivo General de la Administración, Alcalá de Henares (AGA).

En Cádiz realizó tareas de reconocimiento de los “mozos" para dictaminar su exclusión o no del servicio militar, lo cual hizo que visitara diversas localidades gaditanas; pero también este destino parece que le llevó a desempeñar una notable influencia en los ambientes culturales de Cádiz, dado que en julio de 1889 fue nombrado "vicepresidente del Ateneo de dicha localidad, donde participa activamente" (Salas Fernández, 1998; Expediente AGMS).
Hasta aquí esta breve síntesis biográfica, algunos de los aspectos apuntados nos ayudarán a entender cuestiones relacionadas precisamente con su ejercicio profesional en Cádiz y su relación con el catedrático de Higiene Benito Alcina Rancé. Aunque también debemos precisar otros aspectos que se consignan en su expediente militar: se le distingue como un notable especialista en "Higiene y Bacteriología", dominando dos idiomas que sin duda le ayudaron a estar al corriente en los temas médicos de su interés: francés y alemán (Expediente AGMS).

\section{MANUEL MARTÍN SALAZAR, BENITO ALCINA RANCÉ Y OTROS MIEMBROS DE LA ESCUELA MÉDICA GADITANA}

Si traemos a colación en este artículo la figura del gaditano Benito Alcina Rancé (18531902) (figura 4), es porque se puede establecer una conexión directa con Manuel Martín Salazar a través de su monografía sobre la tuberculosis, motivo de nuestro estudio, ya que Benito Alcina le prologa la obra, y consideramos que este no es un hecho casual sino que tiene que ver con la labor que Alcina realiza en el seno de la cátedra de Higiene Privada y Pública en la Facultad de Medicina de Cádiz, y las publicaciones de éste en la década de los ochenta. El hecho de que Martín Salazar estuviera destinado en Cádiz durante varios años y precisamente en el Hospital Militar, paredaño con la Facultad de Medicina, y los intereses comunes de los dos en torno a la Higiene Pública, debió establecer un vínculo hasta el extremo de que Martín Salazar le pidiera a Benito Alcina que le prologara su obra "Higiene de la tisis con arreglo a la nueva doctrina parasitoria”, impresa en Cádiz en 1887, en la calle de la Bomba (actual calle Ceballos), muy cercana también a la Facultad y al Hospital Militar. 


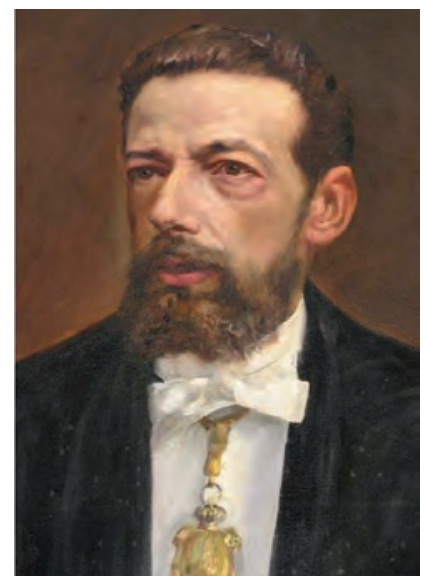

Figura 4: Benito Alcina Rancé (1853-1902). Detalle del cuadro de F. Godoy (salón de grados de la Facultad de Medicina de Cádiz).

Antes de entrar en el análisis de la obra de Manuel Martín Salazar conviene que expongamos los puntos principales de la biografía de Benito Alcina, lo cual nos hará entender la vinculación higiénico-sanitaria de ambos, aunque lo primero que debemos señalar es que los dos pertenecen a la misma Generación ya que solo mediaba un año de diferencia entre sus respectivos nacimientos: Alcina nació en 1853 y Martín Salazar, como queda apuntado, en 1854. La vida de Martín Salazar fue longeva se extendió hasta el año 1936, mientras que la de Alcina se truncó prematuramente en 1902, aunque como puede comprobarse tuvo tiempo de dejar huella en la medicina y en el higienismo gaditano.

Un dato a subrayar es la precocidad de Benito Alcina, ya que en 1879, con 26 años de edad alcanza la cátedra de Higiene Privada y Pública de la Facultad de Medicina de Cádiz (Orozco y Mira, 1982; Herrera, 1998). Alcina participó en el Congreso Regional de Ciencias Médicas, celebrado en Cádiz, en 1879, presentando varios trabajos, de los cuales solo destacaremos aquí "Los climas marítimos y la navegación en el tratamiento higiénico de la tisis tuberculosa". El catedrático gaditano se muestra escéptico con los recursos terapéuticos existentes y defiende la atmósfera marina en el tratamiento del tuberculoso, apoyándose en el estudio de Balfour (1844). Alcina apoya sus afirmaciones con un solo caso de su experiencia personal, un joven tuberculoso de 23 años al que instaló en un buque en la bahía gaditana durante mes y medio, mejorando al parecer de forma significativa, pero la enfermedad se intensificó cuando el paciente desembarcó, atribuyéndolo el higienista gaditano al abandono de la atmósfera marina, por eso se mostraba partidario de crear una Casa de Salud en la Bahía de Cádiz, concretamente en el islote Fort-Louis (Herrera, 1998). También el médico francés René Théophile Laënnec (1781-1827) era partidario de la climatoterapia marina; incluso el poeta John Keats, en 1820, con la enfermedad ya muy avanzada, se embarcó con la esperanza de "que el aire del mar me será muy beneficioso" (Herrera, 2012).

Pero al margen de este comentario sobre la tuberculosis, lo verdaderamente significativo en la biografía de Benito Alcina es que en la década de los ochenta, en la que coincidirá en Cádiz con Manuel Martín Salazar, y más concretamente en enero de 1880, saca a la luz pública la "Gaceta de Higiene y Climatología", que al menos se publicó durante ese año y también en 1881 (Orozco Acuaviva, 1981b). En esta revista Alcina dejó constancia de su trabajo y dedicación a la higiene y la microbiología, teniendo muy presente los trabajos de Pasteur y de Lister, además de señalar las carencias en España de estadísticas médicas fiables (Herrera, 1998). Benito Alcina, en la Facultad de Medicina, creó una Estación Meteorólogica y un Gabinete de Higiene (Orozco Acuaviva, 1981b). Y tuvo como colaborador en la revista a Antonio Mendoza, estudioso de la microbiología, que 
años más tarde brilló en Madrid en el Hospital de San Juan de Dios con su labor docente de las técnicas bacteriológicas, de la cual se beneficiaron Cortezo, Mansilla, Simarro, Hernando, San Martín, etc. (Herrera, 1998).

En noviembre de 1881 se constituyó la sección provincial de Cádiz de la Sociedad Española de Higiene, nombrándose Presidente a Alcina, y al menos desde 1880 actuaba también como Corresponsal extranjero de la Sociedad de Medicina Pública e Higiene Profesional de París. En 1882 participó con una comunicación en el Congreso Médico Internacional de Sevilla, en el cual presentó un aparato original, un "aeroscopio", para recoger del aire el "polvo vivo", siguiendo así la línea de trabajo de Pauchet y Pasteur en los estudios microscópicos de los gérmenes. Además en este mismo año publicó su “Tratado de Higiene Privada y Pública”. En 1883 denunció que la Dirección de Sanidad fuera un puesto ocupado por políticos que desconocen los fundamentos de la Higiene, así como las deficientes leyes sanitarias existentes en España (Herrera, 1998). Entre los años 1884 y 1886, en colaboración con Cayetano del Toro y Quartiellers (1842-1915), publica la revista "Crónicas de especialidades médico-quirúrgicas" (Orozco Acuaviva, 1881c). Aún en el curso 1887-1888, Benito Alcina, sigue explicando en la Facultad de Medicina de Cádiz la asignatura de Higiene Privada y Pública "con nociones de estadística y legislación sanitaria", recuérdese que es precisamente en 1887 cuando prologa la monografía sobre la tuberculosis de Manuel Martín Salazar que comentamos en este artículo.

Pero en 1890, la cátedra de Higiene en Cádiz la desempeña Juan Luis Höhr Rodríguez (1864-1907) (Casas de Ciria, 2012), explicando Benito Alcina en ese año la Terapéutica médica (Orozco y Mira, 1982). También conviene recordar, hecho que no nos parece casual que, en octubre de 1889, Manuel Martín Salazar se presentó, como hemos indicado ya, a la cátedra de Higiene de la Facultad de Medicina de Cádiz, quedando en segundo lugar; si relacionamos hechos todo apunta a que el número 1 en estas oposiciones fue el ya citado Juan Luis Höhr. Cabe señalar también que en 1888, Juan Luis Höhr (figura 5), tan solo un año después de la publicación por Martín Salazar de la monografía sobre la tuberculosis que estudiamos en este artículo, defendió su tesis doctoral sobre la "Etiología y profilaxis de la tuberculosis" (Höhr Rodríguez, 1888) (BFF-UCM), datos que hemos podido corroborar en su expediente personal de doctorado que se encuentra en el Archivo Histórico Nacional (AHN). La carrera profesional del sanluqueño Juan Luis Höhr también fue "meteórica" ya que obtuvo el grado de licenciado en medicina en 1886, incluyendo las calificaciones de sobresaliente y premio en las asignaturas de Higiene Pública y en la de Higiene Privada (Expediente de doctorado, AHN), que impartía el catedrático Benito Alcina Rancé. En plena juventud, Höhr, descubrió una "anema bucali" no descrita (Orozco Acuaviva, 1981a).

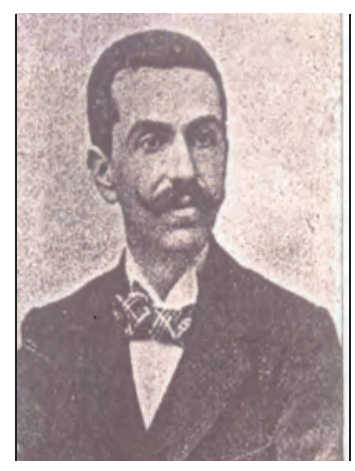

Figura 5: Juan Luis Höhr Rodríguez (1864-1907), médico de Sanlúcar de Barrameda, que sucedió en la cátedra de Higiene a Benito Alcina en la Facultad de Medicina de Cádiz (Fotografía cedida por C. Márquez). 
Curiosamente aún debemos destacar un hecho más; Joaquín Portela González (18691939) (Bartual Pastor y Bartual Magro, 1999) (figura 6), discípulo de Benito Alcina, que subrayó el "arte pedagógico" y las "lecciones admirables" de su maestro (Herrera, 1998), también publicó una monografía en 1889 con el tema "Reflexiones sobre la etiología y tratamiento antiséptico de la tuberculosis", prologándole en esta ocasión su trabajo Juan Luis Höhr Rodríguez (B-FHR). No cabe duda que tanto el trabajo de Höhr como el de Portela nos serán de gran utilidad para someter a contraste algunos aspectos de la monografía sobre la tuberculosis de Manuel Martín Salazar, que como hemos apuntado fue publicada en Cádiz en 1887.

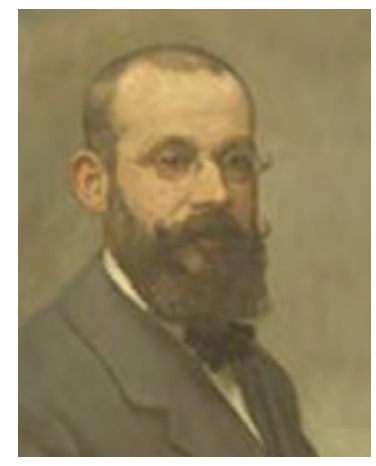

Figura 6: Joaquín Portela González (1869-1939). Fuente: Detalle del cuadro de F. Godoy (Facultad de Medicina de Cádiz).

Todo apunta a que Manuel Martín Salazar, durante su destino militar en Cádiz, mantuvo relación con Benito Alcina y con su círculo, una prueba evidente es el prólogo de la obra que pasamos a comentar a continuación. No debemos olvidar tampoco que en esta década de los ochenta Alcina despliega una intensa labor como profesor de las asignaturas de Higiene Privada y Pública, pero también contribuye a esta disciplina con revistas, comunicaciones, libro y un Gabinete. Martín Salazar, además de la tradición higienista de los médicos de la Armada, debió nutrirse en mayor o menor medida del ambiente propiciado en Cádiz por Benito Alcina, que contaba con ilustres precedentes que no podemos sintetizar aquí (Herrera, 2007). Llama la atención que Benito Alcina reclamara en los años ochenta, como hemos apuntado, la necesidad de que la Dirección de la Sanidad no estuviera en manos de políticos y que al correr de los años Manuel Martín Salazar se convirtiera en una figura de primer nivel al dirigir la Sanidad en España, circunstancia que creemos habría alegrado a Benito Alcina si hubiera tenido ocasión de saberlo, ya que su fallecimiento como hemos indicado fue muy prematuro en 1902.

Pasemos sin más dilaciones, pues, a comentar la obra de Manuel Martín Salazar " $H i$ giene de la tisis con arreglo a la doctrina parasitoria”, publicada en Cádiz en 1887 (Fondo Antiguo BCS-UCA) (figura 7).

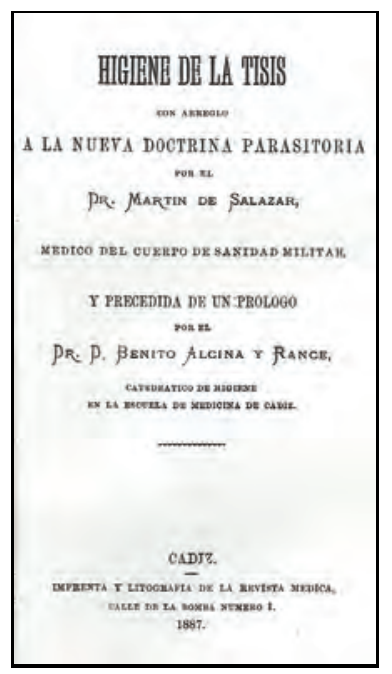

Figura 7: Portada de la monografía de Manuel Martín Salazar sobre la "Higiene de la tisis con arreglo a la nueva doctrina parasitoria" (Cádiz, 1887). Fuente: Fondo antiguo BCS-UCA. 
LA HIGIENE DE LA TISIS SEGÚN MANUEL MARTÍN SALAZAR (1887)

La monografía de Manuel Martín Salazar, además del prólogo que comentaremos en primer lugar, presenta apartados específicos sobre la etiología de la tuberculosis, el contagio, la herencia, la vacunación, la desinfección, la alimentación y el clima, así como epígrafes dedicados a la higiene social y a la tuberculosis en el Ejército. Creemos que no se ha subrayado todavía su importancia, en el contexto del inicio de la obra como higienista de Manuel Martín Salazar; sabemos por su excelente y documentado biógrafo que, en mayo de 1888, se le concedió una mención honorífica a esta monografía, aunque apunta "trabajo del que ya hicimos mención anteriormente y del que tan sólo poseemos una pequeña reseña bibliográfica de A. Quintana, publicada en la Revista de Sanidad Militar de fecha 1 de julio de 1887" (Salas Fernández, 1998).

Centremos, en primer lugar, nuestra atención en el prólogo de la obra escrito por Benito Alcina Rancé. En el mismo, Alcina, habla de "buena amistad" con el autor de la obra, pero sobre todo señala que "urge acostumbrar á médicos y á profanos á que piensen sobre Tuberculosis del mismo modo que se indica en este trabajo". En las primeras líneas del prologuista apunta la crítica a los que se amparan en la práctica y en la tradición para negar la experimentación y añade: "Las cosas, vistas de tal suerte, hacen que el experimentador de hoy salude agradecido y respetuoso al sabio de ayer que le donó materiales á manos llenas, y que éste le felicite á su vez por el buen uso, que del donativo ha hecho". Alcina señala que la monografía de Martín Salazar está escrita desde la perspectiva de la moderna microbiología que permite plantear de manera diferente la prevención de la enfermedad, "a pesar de que la tuberculosis no sea todavía enfermedad generalmente curable".
Encontramos, pues, que Alcina defiende la tradición de los estudiosos de la tuberculosis, desde el punto de vista clínico; pero como era de esperar de su talante científico, aboga por la moderna investigación microbiológica, que él mismo auspiciaba en las revistas anteriormente mencionadas, no dudando en calificar a la tuberculosis como "terrible azote de la Sanidad moderna" y de "endemia devastadora". Incluso encontramos que en sus comentarios prologales sobre la enfermedad reflexiona así: "Será la civilización, causa de la tuberculosis? ¿Será la civilización enemiga de la misma?”. Para Benito Alcina, que no en vano explicaba nociones de estadística en su asignatura en la Facultad de Medicina de Cádiz y que además abogaba por la mejora de las estadísticas sanitarias en España, las elevadas cifras de mortalidad por tuberculosis en las grandes capitales señalan, sin duda, "el mónstruo de la época". Por eso el catedrático gaditano defiende en su prólogo las líneas argumentales generales esgrimidas por Martín Salazar en su monografía, ya que se trata de estudiar tanto "el gérmen tuberculoso como el terreno en que éste pueda sembrarse, siendo esto tan verdadero, que sin aquel, el terreno es infecundo, $y$ sin éste, el gérmen no prospera”. Extinguir los gérmenes de la tuberculosis, evitar su siembra en el organismo, por eso considera perentorio divulgar la "doctrina patogénica actual y prevendremos mucho y combatiremos algo".

Pero centremos ya nuestros comentarios en el texto de Martín Salazar, que se interesa por la tuberculosis por la elevada mortalidad que produce en el mundo (tabla 1), y muy específicamente en España donde la tuberculosis en esa época mataba cada año a 68.000 personas. Su revisión estadística abarca de forma general a los países europeos, pero realiza interesantes reflexiones sobre diversos lugares del mundo, 
incluyendo América, con una alta mortalidad en Brasil, Perú y en las Antillas, donde la tuberculosis es "después del vómito, el gran azote de nuestras tropas y de los españoles en general". En cuanto a grandes capitales señala a París, Londres, Berlín, Viena, Roma, San Petersburgo y Madrid, que "atestan sus necrópolis de tísicos". Una enfermedad, pues, que realiza estragos en las vidas de las personas, sobre todo y con preferencia en las edades comprendidas entre los 15 y los 45 años. Y ante este panorama Martín Salazar se pregunta: “Cómo los hombres soportan con tanta indiferencia estas plagas, con tal de que sean sordas y constantes, y se conmueven, en cambio, tanto, en presencia del cólera por ejemplo, que es, por lo pasajero, mucho menos mortífero y peligroso que la tisis?". Según sus datos son más de 3 millones de personas las que mueren por la tuberculosis en el mundo cada año. Martín Salazar está convencido de que la Higiene es la primera disciplina del Derecho Público y es una ciencia social trascendente, y por estas razones el higienista, desde su experiencia social y científica, debe alzar la voz para llamar la atención de los gobiernos, sobre todo en España, que es de las más castigadas por esta enfermedad en Europa, pero también como militar recuerda que el Ejército español es de los más diezmados en el mundo por la tuberculosis.

Tabla 1: $N^{o}$ de defunciones por tuberculosis (por mil habitantes)

$\begin{array}{lc}\text { PAÍSES } & \text { No DE DEFUNCIONES } \\ \text { HOLANDA } & 4,9 \\ \text { BÉLGICA } & 4,9 \\ \text { FRANCIA } & \text { "Similar" } \\ \text { ALEMANIA } & 4,2 \\ \text { ESPAÑA } & 4 \\ \text { INGLATERRA } & 4 \\ \text { SUIZA } & 2,5\end{array}$

Fuente: Martín Salazar, 1887. Elaboración propia.

\section{La etiología de la tuberculosis}

Martín Salazar tiene claro un precepto, no se puede determinar la medicina preventiva contra una enfermedad, sin antes estudiar la causa "que la instituye como fenómeno positivo y real en la Naturaleza”. De ahí que el médico sevillano insista en que la profilaxis depende de la etiología y su patogénesis, "y por eso ha cambiado tanto la higiene de la tuberculosis, desde el concepto antiguo del tubérculo, hasta los modernos descubrimientos de Koch". Aquí está el nudo gordiano de la monografía de Martín Salazar, existe un antes y un después del descubrimiento del bacilo de la tuberculosis, hecho determinante que marcará la pauta de la medicina preventiva para luchar contra esta enfermedad. Pero existe un problema, y no es otro que la "doctrina parasitaria" de la tuberculosis no es admitida como cierta por toda la comunidad médica, por eso "no hay más remedio que insistir en ella, y demostrar, hasta donde nos sea posible, el origen parasitario indiscutible de la tisis, si por acaso intentamos asentar la higiene sobre base lógica é incontestable". Para Martín Salazar la "doctrina parasitaria" abre un campo a la investigación profiláctica y terapéutica de la tuberculosis.

Entre las autoridades en que se apoya en su texto encontramos a Koch, Pasteur, Darwin, pero llama la atención que se apoye en los argumentos matemáticos esgrimidos en su " $\mathrm{Pa}$ tología general" por José de Letamendi (18281897), concretamente recoge de este autor lo siguiente: “...la intensidad de los efectos parasitorios estará en razón directa de la energía positiva del organismo invasor, y en razón inversa de la energía positiva del organismo invadido". A partir de este apunte letamendiano, Martín Salazar anuncia un principio de higiene general aplicable a todas las enfermedades ocasionadas por "agentes vivos", y en particular 
en la tuberculosis, consistente en combatir al enemigo invasor (el parásito), destruyéndolo o atenuándolo, y fortalecer la energía individual del hombre, "y en general del ser agredido". Así queda planteada la base, según sus criterios, de la lucha contra la tuberculosis.

Se ha señalado que la dialéctica del origen de la tuberculosis se desarrolló en torno a dos elementos, el "germen" y el "terreno", factores que condicionarían el grado, evolución y pronóstico de la enfermedad, de manera que los médicos de la época se adscribieron a distintas posturas según la categoría que le concedieran a uno u otro factor, lo cual repercutía a la hora de reivindicar unas medidas profilácticas $u$ otras para evitar la difusión de la enfermedad. Los "gerministas" consideraban que la principal tarea de la lucha antituberculosa, consistía en cerrar todas las fuentes de contagio, impidiendo que el sano adquiriese el bacilo y por tanto la enfermedad, y los que creían en el contagio a ultranza defendían la declaración obligatoria para recluir a los tuberculosos en sanatorios, mientras que los que daban más importancia al "terreno" afirmaban que lo de menos era el bacilo ya que, si en realidad fueran tan peligroso, la humanidad hubiera desaparecido, pues el bacilo de Koch se encontraba esparcido por doquier (cf. la excelente síntesis que sobre este asunto ha realizado Molero Mesa, 1989). En este sentido creemos que podemos considerar a Martín Salazar como un ecléctico, pero que demuestra un firme convencimiento de que en la lucha contra la tuberculosis es fundamental el descubrimiento de Robert Koch.

Martín Salazar destaca cuatro nombres en la historia del estudio sobre la tuberculosis humana: René Laënnec, Rudolf Virchow, Jean Antoine Villemin y Robert Koch. Laënnec hizo una descripción clínica magistral de la tuberculosis, Virchow estudió su histología patológica y concibió la enfermedad como el resultado de una "erupción neoplásica, pobre y miserable del tejido conjuntivo", sin comprobar que además de este tejido "contribuyen a formar los elementos del tubérculo, células epiteliales y hasta células emigrantes salidas de los vasos sanguíneos y linfáticos". Villemin comparó la tuberculosis con el muermo, y demostró que su inoculación en los animales producía granulaciones semejantes a las de los pulmones de los tuberculosos. Aunque hay autores que señalan a Klencke como el primero en reproducir con éxito la tuberculosis de manera artificial, inoculando material tuberculoso de un ser humano en las venas cervicales de un conejo, provocando en el animal una tuberculosis diseminada en pulmones y riñón (Gutiérrez García, 2003). Y, por último, Robert Koch, que con el descubrimiento del bacilo que lleva su nombre inaugura, según Martín Salazar, "la racional investigación profiláctica y curativa de este padecimiento". Este descubrimiento lleva a algunos investigadores de la época a pensar que el tubérculo no es un tumor de estructura embrionaria especial sino el resultado de una reacción inflamatoria ocasionada en las células por el estímulo de las bacterias de Koch.

Así, pues, los trabajos de Koch, Cornil, Klebs, Toussaint, Malassez y Vignal preconizan la teoría inflamatoria y parasitaria de la tuberculosis. Apunta Martín Salazar al respecto: "Según estos autores, los bacilos en circulación por el torrente sanguíneo o linfático, se detienen en los pequeños vasos, y determinan por su acción irritante sobre los elementos endoteliales, aquella especial proliferación celular que constituye el tubérculo". A todo esto ayuda que el bacilo de Koch es aerobio y encuentra en los pulmones la mayor cantidad de aire posible para su desarrollo, lo que justificaría el predominio de la tuberculosis pulmonar. 
Otros autores de la época matizaban que el bacilo se convierte en un parásito de la célula y esto se traduce por una exageración nutritiva y generadora, primero del núcleo y después del protoplasma, señalando que la inoculación experimental permite seguir atentamente el proceso inflamatorio que representa la formación del tubérculo, por tanto la denominada "neoplasia tuberculosa" no sería más que una hiperplasia de elementos más o menos modificados, cuya evolución defectuosa ha sido motivada por el "gérmen fimógeno" (Portela González, 1889).

Desde la admiración al hallazgo de Koch y a la microbiología en general, Martín Salazar explica que no se puede concebir que la microbiología sea la medicina entera, ya que si no se conocen las condiciones orgánicas que hacen posible el desarrollo del microbio y la reacción natural del organismo "no se tiene, en verdad, gran cosa que pueda utilizarse ni para la medicina ni para la higiene". Se observa, pues, que el médico sevillano aprecia los descubrimientos de Koch, pero sintetiza lo que le parece válido de las viejas opiniones sobre la enfermedad que representan una "tradición secular", sin olvidarse por supuesto del "axioma indiscutible entre los microbiologistas" de los postulados de Koch para asegurar que un microbio es la causa de una determinada enfermedad, recordando que el investigador alemán no solo descubrió el microbio de la tuberculosis en el hombre y en los animales tísicos, sino que dio, a la vez las pruebas científicas requeridas para dejar sentada para siempre la naturaleza bacilar de esta enfermedad cuando publicó sus primeros estudios en abril de 1882.

Koch vio en los esputos de los tuberculosos, en la superficie supurada de las cavernas, en los cortes de los tubérculos miliares y de las producciones tuberculosas de los diversos ór- ganos, unos bacillus delgados, de 3 a 4 milésimas de milímetro de longitud, muy parecidos a los de la lepra, y que coloreaba, sumergiendo las preparaciones durante 24 horas en una mezcla de azul de metileno y una disolución de potasa cáustica al diezmilésimo, método de coloración que posteriormente fue mejorada por Ehrlich. Sin embargo, otros autores preferían el método de Neelsen ya que tiñe intensamente al bacilo empleando la fórmula siguiente: fuchina (1 gramo), fenol (5 gramos), alcohol absoluto (10 gramos) y agua destilada (95 gramos) (Portela González, 1889).

También debe tenerse en cuenta que el descubrimiento de Koch fue puesto en duda por algunos científicos como, por ejemplo, Stemberg, Haricourt, Tulasne, Spina, Craemer o Balong, incluso Schmidth confundía el bacilo con cristales de grasa, mientras que Gregg lo consideraba como filamentos de fibrina, y Beneke y Cuter lo aceptaron pero como formas embrionarias del "micoderma aceti" (Höhr Rodríguez, 1888). Martín Salazar, revisando los estudios de los autores de mediados del siglo XIX, señala la gran intuición que tuvieron algunos cuando defendieron "la identidad efectiva de la tisis y la escrófula, que había de venir á darles la razón la microbiología moderna, nada menos que con prueba plena, como es la de encontrar el bacillus de Koch en las lesiones escrofulosas, y ocasionar la tuberculosis generalizada en los animales con inoculación experimental de los productos escrofulosos".

\section{Ideas sobre el contagio y la herencia}

Martín Salazar parte de que Hipócrates refleja en su obra la existencia de una epidemia de tisis en la isla de Thassos, y de que Galeno y los médicos árabes creyeron siempre en la contagiosidad de esta enfermedad; en cambio, el médico sevillano comenta que él mismo ha 
visto a médicos explicar la no contagiosidad de la enfermedad, por eso valora la reacción a favor del contagio que suscitaron los experimentos de Villemin, Chauveau y Tappeiner, este último demostrando el contagio por la vía respiratoria en animales, mientras que los otros autores citados lo hicieron a base de inoculaciones debajo de la piel de los conejos o haciendo ingerir esputos de tísicos también en animales, mientras que Klebs hacia lo propio con leche de vacas tuberculosas. Incluso cita el desgraciado accidente de Laënnec, que al serrar vértebras de un cadáver tuberculoso durante una autopsia se hirió un dedo, " $y$ todo el mundo sabe que este ilustre médico murió de tuberculosis pulmonar", aunque también se ha apuntado que el médico francés pensaba que la tuberculosis no era contagiosa (Herrera, 2012).

Además de lo expresado se debe consignar que en la bibliografía de la época se argumenta sobre el "contagio por inoculación directa", a través del atroz experimento realizado por Demet, Paraskova y Zablonis, tres médicos griegos que inocularon esputos tuberculosos en la pierna de un enfermo que padecía gangrena del pie, comprobando que a las tres semanas existían alteraciones en el pulmón derecho, falleciendo a los 38 días el paciente al parecer de la enfermedad primitiva, demostrándose en la autopsia la existencia de tubérculos pulmonares que "se encontraban en un periodo de desarrollo correspondiente á la fecha de la inoculación" (Portela González, 1889).

Desde el punto de vista de Martín Salazar es indudable que por la respiración de un aire lleno de partículas tisiógenas, que contengan muchos bacilos de Koch, es como se produce la mayoría de las veces la infección tuberculosa. Cita, como ejemplo, el caso de una comadrona de Núremberg, enferma de tuberculosis, que acostumbraba a hacer la insuflación directa con su boca a los niños recién nacidos, en corto plazo de tiempo murieron por meningitis tuberculosa más de diez pequeños asistidos por esta mujer; mientras que en la misma población otra comadrona, sana, no perdió por afección tuberculosa ninguno de los niños asistidos. Sin embargo, se debe apuntar que en la época había autores que consideraban que el contagio de la tuberculosis mediante el aire era poco seguro ya que consideraban que la presencia del bacilo de Koch en la atmósfera que rodea al tísico no ha sido plenamente demostrada, creyendo además que los "productos morbosos" después de desecados pierden "su virulencia por haberse acompañado de un proceso de putrefacción". Sí podían admitir algunos el papel contagiante de los esputos, "infeccionando la atmósfera con los bacilos que contienen", pero consideraban que esto solo ocurría en casos de tos, acto mecánico destinado a dividir en finas partículas el producto de la expectoración que arrastra, sustentando que en cambio el aire espirado por los tísicos y exhalado directamente sobre la boca de un individuo sano no tiene este mismo poder, " $y$ que por lo tanto el aire expirado jamás podrá ocasionar la infección”. Autores como Cohnheind y Verneuil admitían el contagio mediante las relaciones sexuales (Höhr Rodríguez, 1888). Como vemos el debate sobre el contagio estaba abierto en la época, por eso conviene profundizar un poco más en las ideas plasmadas al respecto por Martín Salazar en su monografía.

Martín Salazar le da mucho valor a las partículas de los esputos desecados, confundidas con el polvo atmosférico y arrastradas por el viento, en la producción de la infección respiratoria, aunque las partículas desecadas de las heces fecales, de la orina y de otras secreciones donde se ha reconocido el bacilo de Koch po- 
drían "inficionar el aire". Igualmente da gran valor a la transmisibilidad de la tuberculosis por la alimentación con sustancias procedentes de animales tísicos, en este sentido "la leche ha sido el alimento más acusado". En cambio señala que las investigaciones de la época no han podido obtener resultados concluyentes sobre si la sangre, las carnes y las vísceras de los bovinos atacados por la tisis, usados como alimentos, podrían ocasionar la enfermedad. En cuanto a las gallináceas, alimento muy común del hombre, se han encontrado bacilos en los tubérculos de los pollos, demostrando Nocard el contagio del hombre a las gallina, pero en opinión de Martín Salazar no parece fácil el contagio por la alimentación dada la acidez del jugo gástrico, además de las preparaciones culinarias, "quitando por el calor todo poder tisiógeno á los alimentos". Desaconseja no utilizar vacunas que procedan de personas o de terneras enfermas de tuberculosis.

En cuanto a la herencia, Martín Salazar se hace una pregunta: $¿$ se nace tuberculoso o se nace "tuberculizable"? Cuestión a la que responde "que se puede heredar, ó la semilla en germinación, ó el terreno adecuado para germinar". Cita la experiencia de Demme que encontró en los pulmones de dos niños tísicos, muertos a los pocos días de nacer, cavernas extensas y profundas "que probaban la infección tuberculosa durante la vida fetal". De manera que Martín Salazar se muestra categórico, no se puede negar en absoluto la herencia directa por la madre, manifestando que se puede producir mediante la sangre placentaria de la madre tísica "ó por impregnación primitiva tuberculosa del óvulo", sin descartar la sospecha de la posibilidad de la infección del feto por el esperma del padre, sin contaminación alguna de la madre, aspectos en los cuales la investigación se encuentra en estado muy primario como para dar respuestas categóricas, aunque cita que Niepce encontró bacilos en el esperma de hombres tuberculosos. Autores, como Juan Luis Höhr (1888), apoyándose en los trabajos de Jani, Landouzy, Martín, Chamberland y Strauss eran partidarios de la herencia paterna de la tuberculosis, pero se mostraban aún más partidario de lo que denominaban "heredo-tuberculosis por semilla materna", considerando una evidencia "el paso posible de las bacterias de la sangre materna á la del feto". Otros autores daban por sentada la transmisión por herencia de forma más categórica, y no solo la herencia de la predisposición sino también la del germen, argumentando "que estudios y experiencias han demostrado que á más del terreno abonado, puede trasmitirse hereditariamente en muchos casos la enfermedad misma", apoyándose sus argumentos en las estadísticas de Parrot, West, Wahl y Lannelongue. Parrot, por ejemplo, presentó 219 observaciones de tuberculosis, desarrolladas antes de los 2 años, diagnosticando la tuberculosis en 23 niños cuyas edades estaban comprendidas entre 1 día y 3 meses, en todas esas observaciones se comprobaron en la autopsia lesiones específicas más o menos avanzadas en los pulmones y otros órganos como laringe, hígado, intestinos y meninges, argumentos que consideran suficientes para demostrar que la "tuberculización" no es infrecuente en las primeras edades, en este sentido autores como Baumgarten y Vallin pensaban que el origen de la enfermedad había que buscarlo en el contagio ulterior, ocurrido muy principalmente por la lactancia, en cambio otros autores abogaban a favor de la transmisión de la enfermedad durante la vida intrauterina, apoyando sus argumentos en los fetos tuberculosos observados por Chaweau, Peter y Jonhe (Portela González, 1889). En la actualidad se admite que la bacteriemia tuberculosa 
que ocurre durante el embarazo puede resultar en infección de la placenta o del aparato genital materno, esta transmisión puede ser transmitida al feto por rotura de un tubérculo de la placenta produciéndose difusión hematógena por vía del cordón umbilical, o bien a partir de una afección de los genitales de la madre produciéndose aspiración o deglución del líquido amniótico o sangre infectados (Soza, Cala y Mantilla, 2007). Se entiende, pues, el debate existente al respecto a finales del siglo XIX, porque hoy día la tuberculosis congénita es de difícil diagnóstico y requiere de un alto grado de sospecha, debido a la falta de especifidad de las manifestaciones, ya que usualmente hay compromiso multisistémico y a que en la mayoría de las ocasiones se desconoce el estado infeccioso de la madre (Soza, Cala y Mantilla, 2007).

De toda esta cuestión sobre la herencia y tuberculosis, comprobamos también una opinión de carácter eugenésico en el discurso de Martín Salazar: "los matrimonios entre tuberculosos, constituyen un verdadero mal para la sociedad"; planteándose cuestiones éticas sobre si la higiene social debe intervenir en las leyes matrimoniales o incluso autorizarse el divorcio por "tuberculización" de uno de los cónyuges. En este sentido, Martín Salazar, se muestra categórico calificando de inmoral este tipo de intervenciones, argumentando que con estas medidas no dejarían los tísicos de reproducirse y se incentivaría la prostitución, el concubinato y el adulterio, consiguiendo con todo ello que los enfermos no encuentren el calor, el consuelo, los cuidados y hasta "el heroísmo de la familia”.

\section{Vacuna, desinfección, alimentación y clima}

La cuestión que plantea el médico sevillano sobre la vacuna o "inoculación preservativa" es la siguiente: “¿Es de esperar, ya que la tuberculosis es una enfermedad infecciosa, como la viruela, como el carbunco, etc., que andando el tiempo (...) llegue el día en que se descubra la vacuna de la tuberculosis?”. En este punto se muestra pesimista ya que considera que tampoco es de esperar que se descubra la del paludismo, la de la erisipela, la de la blenorragia, ni la de ninguna de esas enfermedades parasitarias, "que en vez de dar inmunidad, dan, por el contrario, mayor predisposición”, aunque no descarta sorpresas del genio científico e investigador de su época, de cuya muestra pone como ejemplos los experimentos con animales realizados por Martín, Parrot, Falk y Gosselin, resultando sus experiencias negativas. Recuérdese, como apuntó Portela González (1889), el intento de Cantani con la "bacterio-terapia", que consistía en establecer una lucha por la existencia entre el bacilo de Koch y el "bacterium termo", a fin de lograr el exterminio del primero.

Vistos estos fracasos señala Martín Salazar que autores como Gosselín, Raymon y Arthaud han cambiado la orientación de sus investigaciones empeñándose en "hacer estéril el organismo, merced á sustancias antizimóticas que lo impregnen, y que le coloquen á salvo del ataque fatal del bacilus de la tuberculosis". En esta línea se experimentó con el poder preservativo del bicloruro y del yoduro de mercurio, del sulfuro de carbono, del yodoformo y del tanino, pero salvo estos dos últimos que parecen haber detenido algo el desarrollo de la tuberculosis experimental, las demás sustancias, hasta la han favorecido por la debilitación orgánica que producen en los animales utilizados en la experimentación. Martín Salazar se muestra escéptico que por este camino se llegue a resultados prácticos en la preservación de ninguna enfermedad, ya que no se puede 
condenar a una persona, con el pretexto de salvarle de la tuberculosis, al uso diario de medicamentos antisépticos que minarán con el tiempo su salud, resultando la profilaxis peor que la enfermedad. Además se debe tener en cuenta que la supuesta preservación instituida por el medicamento no durará sino el tiempo que se tarde en eliminar, "mientras que la preservación dada por la vacuna, equivaldrá siempre á la inmunidad natural que deje en el organismo el padecimiento que se intente precaver".

Pero otra cosa distinta es la idea de destruir el bacilo de Koch en el organismo de los enfermos, en los esputos, en las excreciones, en el suelo, en el aire, sobre las cubiertas de la cama, en los vestidos, en los alimentos, en las habitaciones, en los objetos que utilizan los tísicos, en los animales tuberculosos, en todas partes donde pueda vivir el microbio y multiplicarse, " $y$ de alguna suerte inficionar el organismo del hombre". En esta línea, Martín Salazar expone los experimentos de Schüller y Fischer con el alcohol absoluto, el amoniaco cáustico, el licor de Van-Swieten, las disoluciones concentradas de ácido salicílico, de permanganato potásico, de ácido fénico, de cloruro de zinc, de ácido tímico y de sulfato de cobre, que "han esterilizado por completo los esputos frescos de los tísicos".

Otros autores realizaron tentativas, entre otras sustancias con la creosota, el eucaliptol, el ioduro potásico, el arsénico, el ácido pícrico, la fenilamina, el mercuretilo, el mentol, la helenina, la trementina, el terpinol, el ácido sulfuroso, el cloro, etc. Los resultados prácticos dejaron mucho que desear, aunque algunos se empeñasen en resaltar la acción específica de determinados compuestos, circunstancia que llevó a un cierto pesimismo sobre la posibilidad de encontrar un tratamiento etiológico de la tuberculosis (Portela González, 1889). Este pesimismo sobre la terapéutica queda de manifiesto también en el siguiente párrafo de Juan Luis Höhr Rodríguez (1889):

“...debemos convenir en que la terapéutica de la tuberculosis pulmonar no está en poseer un desinfectante que por acción interna ó externa, mate al bacilo tuberculoso ó evite su multiplicación. Dá pena de ver hombres tan conspicuos como el microbiólogo inglés Klein, medir la virtud terapéutica de un agente por la disminución mayor ó menor que se observa en el número de bacilos que el esputo presenta. Aun cuando fuera posible encontrar ese antiséptico ideal que otros como él buscan en vano, no se debe olvidar que existe una relación tan estrecha entre la tuberculosis y la tisis pulmonar que mientras quede el tubérculo, aun purgado de bacilo, queda un inminente peligro de tisis, á no ser que el individuo viva en un medio aséptico en absoluto que libre á sus pulmones de microbios piógenos".

Pero para Martín Salazar el gran descubrimiento es el de la esterilización de los esputos tuberculosos por medio del agua hirviendo o del vapor de agua caliente, durante algunos minutos, "con estos dos sencillos y económicos medios de desinfección, tiene la higiene bastante para purificar casi todas las cosas suspectas de contaminación tuberculosa". En este sentido apela a los experimentos de Frerichs que hizo inoculaciones en los animales con esputos tuberculosos, "cocidos ó desinfectados con el agua hirviendo", y no pudo nunca producir la tuberculosis experimental. De todo ello se desprende, según el médico sevillano, una recomendación que conviene transcribir con detalle, ya que plantea un precepto de carácter higiénico y práctico:

"Por eso, lo que más importa, es desinfectar los esputos en el momento mismo de ser expectorados. A este fin, conviene aconsejar á los tísicos 
que no escupan en el suelo, ni sobre las ropas, donde fácilmente se transforman los esputos en polvo dañoso para la salud de los demás; sino que arrojen su expectoración en vasos ó escupidores que contengan, ó serrín de madera para quemarlo después, ó disoluciones antisépticas, en las cuales entre una cierta cantidad de glicerina ó de otra sustancia higroscópica cualquiera, que pueda impedir los peligros de una rápida evaporación. Estos vasos se vaciarán una ó dos veces al día, y serán después cuidadosamente lavados y desinfectados con el agua hirviendo. Otro tanto convendrá hacer con las vasijas que reciban las deposiciones diarréicas".

Añade que los vestidos y las ropas de cama de los tísicos no deben utilizarse hasta que no hayan sido lavados y desinfectados convenientemente en una cámara de vapor, de no ser posible bastará hervirlos en agua agregándole una solución salina cualquiera. Los utensilios y los muebles pueden desinfectarse con el agua hirviendo o con un chorro fuerte de vapor de agua. Martín Salazar recuerda también que Jaccoud recomienda para el saneamiento de la atmósfera de los tuberculosos, las pulverizaciones de ácido fénico o de benzoato de sosa en el aire de las habitaciones de los enfermos. Pero ante estas recomendaciones prácticas encontramos un comentario escéptico de Martín Salazar: "Tiempo ha de tardar en que estas sencillas prácticas de desinfección se encarnen en las costumbres, mientras anden por ahí vigentes las ideas contrarias al contagio".

El control de los alimentos también es un tema subrayado por Martín Salazar en su monografía; por ejemplo, debe cuidarse la pureza y la inocuidad de la leche, por lo que es preciso inspeccionar la salud de los animales que abastecen de leche a los mercados, realizar análisis microbiológicos para impedir su uso en caso de que se descubra el bacilo de Koch y reco- mienda que se tome la leche hervida: "Hipólito Martín ha demostrado que a los 100 grados pierde el virus tuberculoso todas sus propiedades nocivas". Preconiza también evitar el uso de alimentos de carnes y vísceras procedentes de animales tuberculosos, apuntando que Vallín ha demostrado que las carnes asadas solo llegan por dentro a la temperatura de 58 grados y Toussaint ha probado experimentalmente que a los 75 grados pueden aún "conservar los músculos su virulencia”. Por eso Martín Salazar cree que los higienistas deben plantear la prohibición terminante del consumo de reses tuberculosas, apoyándose en las ideas expuestas por Bouley en el Congreso Veterinario internacional de Bruselas (1883), aunque las conclusiones aceptadas por la Asamblea no fueron tan absolutas como las que proponía este autor ya que se inclinaron por tolerar el libre consumo de las reses, siempre que estando en el primer periodo de la tisis, no tuvieran interesado más que un órgano que fácilmente pudiera ser eliminado. En la misma línea se pronunció el Congreso de Higiene de la Haya (1884) y el Congreso Veterinario de París (1886), todo lo cual decepciona a Martín Salazar que piensa: "...nosotros creemos con Bouley, que todo lo que no sea tomar una medida radical, es correr el riesgo seguro de autorizar el consumo de carnes $y$ vísceras tuberculosas. La medicina veterinaria no puede decir siempre, hasta donde, habiéndose tuberculizado un órgano, puedan estar sanas las vías linfáticas y sanguíneas,...”. Todo ello aún teniendo en cuenta sus ideas, como se expuso anteriormente, del papel jugado por la cocción de los alimentos y de la acción salutífera del jugo gástrico.

Debemos apuntar que se han realizado investigaciones muy serias que giran en torno a la tuberculosis bovina como zoonosis en la España Contemporánea (1850-1950), que tie- 
nen en cuenta este asunto también en el "periodo antemicrobiano" (1830-1882), así como a partir del descubrimiento del bacilo de Koch, analizando asimismo el problema de la carne y de la leche como factor de transmisión de la tuberculosis bovina, y la epidemiología de la tuberculosis de origen bovino en la especie humana (Gutiérrez García, 2003).

Martín Salazar opina, con respecto a las gallinas, que no son suficientemente inspeccionadas antes de exponerlas en el mercado. Por eso reclama que los poderes públicos deben comprender la utilidad de una "ley de policía veterinaria, que, protegiendo la salud y la vida de los animales que padecen la tuberculosis, al par que favoreciera los intereses de la agricultura, coadyuvara de un modo poderoso á la extinción de uno de los principales orígenes de la tuberculosis humana”.

En este apartado quedan dos puntos por aclarar: el régimen alimenticio y el clima más propicios para fortalecer el organismo contra la enfermedad. En la primera cuestión Martín Salazar se decanta por un régimen alimenticio altamente nutritivo: alimentos azoados, carnes, vinos generosos, las grasas y el aceite de hígado de bacalao. Tiene claro que la tuberculosis es una enfermedad de las grandes poblaciones y que se padece muy poco en los campos, gracias a la atmósfera pura. Considera ideales los países montañosos y de cierta altura sobre el nivel del mar para evitar la enfermedad. Los climas cálidos enervan y agotan las fuerzas, y los climas fríos ocasionan fluxiones del aparato respiratorio, por eso considera como más adecuados los climas templados, sin bruscos cambios atmosféricos, como el de Niza, Málaga, Alicante, Murcia, etc. Apunta la hidroterapia y los baños de mar como medios excelentes para fortificar el cuerpo, "por su acción tónica generalmente especialísima”. Señala a la "gimnástica pulmonar" como un remedio de gran utilidad contra la tuberculosis, ya que hace entrar "en función forzada y tonificar los vértices pulmonares que son los más expuestos á la tuberculización".

\section{Higiene social y la tuberculosis en el Ejército}

Para Martín Salazar la misión de la Higiene es aconsejar, instruir, civilizar, señalar el peligro, ofrecer el remedio, y respetar la voluntad de los hombres, ya que de ahí nace la libertad "como principio informador de la moderna organización política de los pueblos". Esta idea la apunta en el contexto que ya hemos comentado del debate sobre la prohibición de los matrimonios entre tuberculosos, considerando que la interferencia de la higiene social en las leyes matrimoniales "sería erróneo y además profundamente inmoral".

El papel de la Higiene social, para Martín Salazar, ya sea en el debate ético que hemos planteado o bien en la lucha contra la enfermedad en el seno de las escuelas, los talleres, los asilos, las cárceles, los conventos, los hospitales o los cuarteles, es de gran importancia porque se trata de evitar el contagio allí donde se produce la aglomeración de los hombres, por eso insiste también en la familia, sobre todo "por la mancomunidad del aire que respira, del alimento que come y de todas las condiciones cósmicas que le rodean, constituye el principal foco de propagación de la tuberculosis".

Dos medios señala el médico sevillano para evitar el contagio: la desinfección y el aislamiento. En la primera cuestión hemos insistido ya en párrafos precedentes, pero conviene apuntar algunos aspectos sobre el "alejamiento de los enfermos". Vuelve a insistir en la tuberculosis en la familia y en el matrimonio, pero midiendo lo que escribe. Para Martín Salazar es conveniente "aconsejar" a los matrimonios 
la separación del lecho "cuando se haga tísico alguno de los cónyuges; y en general, á las familias, que coloquen a los enfermos en lugar aislado, y donde nadie respire constantemente la atmósfera infectada por los productos de escreción y secreción de los tísicos". Pero, inmediatamente, matiza sus palabras:

“...entiéndase bien, que al hablar de aislamiento en el interior de la familia, ha de ser mientras resulte compatible con los altos deberes de humanidad, y con el perfecto cuidado y la asidua y cariñosa asistencia de los enfermos. $\mathrm{Ni}$ la higiene, ni nadie podrá legislar sobre lo material con menoscabo y hasta con mengua de la moral; que la salud del alma será eternamente preferible á la salud del cuerpo; y que cuando toque morir al lado de nuestros padres $y$ de nuestras esposas y de nuestros hijos, nadie podrá volver la cabeza atrás".

Este párrafo está escrito por un médico que está al corriente de las prescripciones de segregación de, por ejemplo, tuberculosos y sifilíticos, pero que en cambio no se entrega a la idea del radical apartamiento social que preconizan algunos higienistas. Su discurso sobre la enfermedad en el medio familiar, le obliga a matizar el problema de la profilaxis en las escuelas, en los talleres, en los conventos y en las cárceles, aquí sí apunta "la separación de los individuos tísicos, y una escrupulosa ventilación y desinfección de los locales". Y en lo que se refiere a los hospitales, defiende el ejemplo de la Sanidad militar, reclamando para los hospitales civiles la creación de salas especiales para los tuberculosos, "para que no siga dándose el tristísimo espectáculo de la contaminación de unos enfermos por otros". Para Martín Salazar no es de recibo que alguien que va a buscar su salud en un hospital por otra causa termine por dejar su vida por causa de la infección tuberculosa. Por todo ello las personas que atiendan en es- tas salas específicas no deben trabajar en otras dependencias del hospital y las prácticas de desinfección deben llevarse a cabo en los hospitales con todo rigor.

Martín Salazar reclama que la moderna Higiene Pública debe abogar por el aire puro, alimentos sanos y abundantes, luz vivificadora, suelos llenos de hermosa y lozana vegetación; habitaciones espaciosas; ciudades modernas, más salubres, con anchas calles, jardines, alamedas, "su sistema de perfecto enmadronamientos, sus aguas puras y potables; $y$ á todo esto, habría que agregar: el problema de la miseria resuelto...”. El médico sevillano escribe párrafos llenos de sentido común y aboga utópicamente por la ilustración y el saber, además de la riqueza y felicidad prodigada a la humanidad entera. Así, y solo así, "veríamos como desaparecía la tisis, que arrastra hoy al sepulcro más de tres millones de habitantes de los más pobres, orgánicamente hablando, que pueblan este planeta en que vivimos".

Un capítulo dedica Martín Salazar a lo que era una de sus grandes preocupaciones en el momento de redactar la monografía: la tuberculosis en el Ejército, ya que la enfermedad es más frecuente en esta institución que en las clases civiles. Maneja cifras precisas de Inglaterra y Francia señalando que el número de muertos e inutilizados por la tisis en estos países asciende a 7,82 por 1.000 , siendo en España la estadística muy parecida. El médico sevillano opina que urge reformar el cuadro de exenciones físicas vigente en España, tema que dominaba ya que en el Hospital Militar de Cádiz durante algunos años se dedicó al reconocimiento de los "mozos" que quedaban excluidos de la obligatoriedad de realizar el servicio militar. Y en esto es muy claro: "La tuberculosis en todas sus formas y en todos sus periodos debe eximir del servicio de las armas, y la ley 
debe expresarlo así, clara y terminantemente. Como enfermedad contagiosa, como enfermedad casi incurable y como enfermedad que recae siempre en organismos de debilidad general muy graduada, debe ser en absoluto causa de inutilidad". Se trata con esta medida de que los tuberculosos sean enviados a sus casas, donde pueden mejorar y recibir cuidados, y que no permanezcan en los cuarteles y hospitales militares, evitándose así los contagios. Recuérdese que en los congresos antituberculosos celebrados en la España de la Restauración, algunas de las ponencias presentadas defendían la ampliación del cuadro de exenciones a los llamados "pretuberculosos" (tórax estrecho, talla corta y delgadez acentuada) (Molero Mesa, 1987).

Unos años más tarde, en 1905, encontramos que Martín Salazar visitó los hospitales militares de Prusia, de Sajonia y de Baviera, y pregunta por las salas de tuberculosos, comprobando, en el hospital de Tempeloff (Berlín), que la clínica de tuberculosis está cerrada y sin un solo enfermo. Y se pregunta lo siguiente: ¿Qué hacen para obtener este sorprendente resultado? Pues muy sencillo: no admitir al ingreso, ni tolerar un momento la existencia dentro del ejército, no ya de los enfermos, sino de los sospechosos, de los simplemente predispuestos á contraer la tuberculosis". Ante este hecho considera que países como Alemania han progresado más que España en la higiene de sus ejércitos, disminuyendo cada vez más y de un modo notable sus cifras de morbilidad y de mortalidad (Martín de Salazar, 1905).

En su monografía, publicada en 1887, centra también sus críticas en el estado de los cuarteles en España que, según su opinión, no son para reformarlos sino para abandonarlos, ya que estos edificios enormes, largos, profundos, de escaleras y corredores sombríos, mal ventilados, albergan unos 2.000 hombres bajo el mismo techo. Los cuarteles deben construirse fuera de las ciudades, vertebrándolos en 20 pabellones aislados unos de otros; este tipo de reformas ha llevado a Austria y a Alemania a reducir notablemente la tuberculosis.

El ejercicio físico, la reducción del tiempo de servicio militar y la alimentación del soldado son elementos a tener muy en cuenta para luchar contra la tuberculosis en el Ejército. En lo que se refiere a la alimentación, Martín Salazar apunta que las tropas españolas reciben pocas "sustancias azoadas". La carne en cantidad suficiente, el vino y el café deben ser de uso ordinario en la alimentación de los soldados, así como el abrigo para evitar los enfriamientos.

Construcción, pues, de hospitales y cuarteles ya que España pierde "capital humano por falta de higiene en el ejército". Martín Salazar recuerda en 1887 que el ejército español es de los más diezmados del mundo por la tuberculosis y por las enfermedades en general, y así lo seguiría siendo en los años siguientes; un ejemplo claro lo constituye la campaña militar cubana, tan solo en el año 1896 la tuberculosis, la fiebre amarilla, el paludismo, la fiebre tifoidea y la disentería causaron una extraordinaria morbilidad y mortalidad, muy superiores al del número de heridos en acciones bélicas (Rico-Avello, 1969). Se entiende, pues, que Martín Salazar incluya como corolario final de su monografía sobre la tuberculosis un capítulo con propuestas de reformas para la mejora de la vida diaria del soldado en los cuarteles y en los hospitales militares.

\section{EPÍLOGO}

En la España de la Restauración, según ha apuntado Molero Mesa (1987), destacaron los estudios sobre la tuberculosis de Federico Gu- 
tiérrez Jiménez (1875), León Corral y Maestro (1884) José Moreno Fernández (1889), Francisco Moliner y Nicolás (1896), José Verdes Montenegro (1902), Vicente Guerra Cortés (1903), Bernabé Malo de Póveda (1908), Vicente Álvarez (1912), (1914), José Chabás (1914), José Codina Castellví (1920), etc. Sin olvidarnos de la importante labor divulgadora y clínica dentro del campo de la tisiología realizada por Antonio Espina y Capo (1850-1930). Y no olvidemos los impresionantes estudios realizados por Philiph Hauser (1832-1925), pionero de la encuesta sanitaria, y autor de obras sociosanitarias sobre Sevilla y Madrid, preocupándose también entre otras cuestiones sobre el pauperismo en Andalucía (1884), la casa y el suelo en relación con las enfermedades (1885) o la defensa social de la tuberculosis (1898) (Del Moral, 1979; Hauser, 1979, 1990; Carrillo, 1996; Rodríguez Ocaña, 1996; Porras Gallo, 1996).

Se ha señalado a la tuberculosis como el prototipo de la enfermedad social infectocontagiosa crónica; en España, por ejemplo, las tasas de mortalidad específica señalan 200 defunciones por cien mil habitantes para el periodo que abarca de 1860 a 1900, y para este último año la cifra apunta 200,6. Igualmente se ha apuntado que la tuberculosis es una de las enfermedades más claramente asociada a la pobreza, destacando entre las investigaciones que pusieron de relieve la acusada desigualdad de su distribución por clases sociales las realizadas por Vicente Guerra Cortés en su trabajo "La tuberculosis del proletariado en Madrid" (1904) (López Piñero, 1990).

Este texto de Martín Salazar publicado en Cádiz, en 1887, es una notable reflexión sobre los conocimientos científicos, epidemiológicos y sociales de la tuberculosis en la España de la Restauración, y no deben ser desatendidas sus apreciaciones porque permiten comprender la situación social y el debate científico generado sobre esta enfermedad en su época, abordando la prevención de la misma desde la perspectiva del descubrimiento bacteriológico de Robert Koch (cf. al respecto a Coury, 1972; Báguena Cervellera, 1992); hecho que generó debate sobre la etiología de la enfermedad, con partidarios y detractores, tan solo cabe recordar en este sentido la reacción de Rudolf Virchow ante las investigaciones de Koch (Lederman, 2003). De igual manera, como hemos podido comprobar, el médico sevillano se esmera con meticulosidad en el debate sobre el contagio de la enfermedad, cuestiones que entre otras han sido estudiadas en sus trabajos por Molero Mesa (1987; 1989; 1990), así como también cabe significar los problemas de la "habitación”, la arquitectura y la salud pública en el periodo señalado (Bernabeu Mestre, 2009; Huertas, 2002). Sin olvidar el tema del control de la calidad de la alimentación, cuestión que en relación al "Urban Penalty" han estudiado recientemente Guillem Llobat y Perdiguero Gil (2014).

Téngase en cuenta que en 1882, año del descubrimiento del bacilo de Koch, en el IV Congreso Internacional de Higiene, en Ginebra, se definió a la tuberculosis como una enfermedad contagiosa y que en 1888, en París, se celebró el primero de la serie de los congresos internacionales sobre la tuberculosis, de los cuales emanaron una serie de medidas profilácticas, señal de la gran preocupación que generaba la enfermedad, ya que se ha llegado a apuntar que en la Europa anterior al descubrimiento de Robert Koch una de cada siete muertes se debía a la tuberculosis (Villanueva Edo, 1988). Y siguió preocupando en los años siguientes, tan solo hay que recordar que el médico de la Armada, Ángel Fernández-Caro, en 1912, en 
el Congreso dedicado a la tuberculosis en San Sebastián, también se mostró pesimista al afirmar que "...hoy la tuberculosis produce tantas víctimas como producía hace cincuenta años, $y$ es de temer que siga produciéndolas..." (Herrera, 2002). Y no se equivocó en su apreciación Fernández-Caro, ya que la Organización Mundial de la Salud estima que en 2014 en el mundo se produjeron 9,6 millones de enfermos y 1,5 millones de muertes por tuberculosis, y en el mismo año en España se notificaron 5.018 casos, lo que corresponde a una tasa de incidencia de 10,8 casos por cien mil habitantes (Centro Nacional de Epidemiología, Instituto de Salud Carlos III, 2015), aunque también se debe tener en cuenta que en 1997 en España la incidencia era de 60 nuevos casos por cien mil habitantes, relacionándose este hecho con la inmigración (Carceller y Lebel, 2005).

Martín Salazar, en los años posteriores a la publicación de su monografía sobre la tuberculosis, siguió insistiendo en el gran problema que suponía esta enfermedad en nuestro país, sin ir más lejos en su discurso "La Sanidad en España”, publicado en 1913 (BFM-UCM), denunció la alta mortalidad por tuberculosis en el primer quinquenio del siglo XX en Oviedo, Cádiz (6,39 por mil habitantes), Huelva, Sevilla, San Sebastián (Herrera, 1997, 2007). Se ha señalado, por ejemplo, que en la población bilbaína, entre 1878 y 1885 , entre el 5,1\% y el $6,6 \%$ de las defunciones fueron ocasionadas por la tuberculosis, siendo atribuidas estas cifras tan altas a la mayor afluencia de inmigrantes en Vizcaya (Villanueva Edo, 1988; Urkia Etxabe, 1992), también se ha estudiado la incidencia de la lucha antituberculosa en la mortalidad de la población valenciana (1882-1914) y en el primer tercio del siglo XX (Báguena Cervellera, 1991; Barona, 2007), así como la evolución de la mortalidad en Madrid en el periodo 1883-1925 (Porras Gallo, 1996), y recientemente se ha comprobado las altas cifras de mortalidad ocasionadas por la tuberculosis en Cádiz en los primeros años del siglo XX (Rodríguez Aguado, 2015). Incluso se ha señalado que la imagen de Sevilla sufrió un proceso de deterioro, en la segunda mitad del siglo XIX, "hasta el punto de considerársela como una ciudad altamente peligrosa para vivir", teniendo mucho que ver en esto el aumento de las enfermedades infecciosas (Carrillo, 1998), cuestión que cuenta con un estudio específico de la mortalidad en Sevilla durante la Restauración (1875-1924) (Bernal-Borrego, 1994). En octubre de 1901, se publicó en la Gaceta de Madrid, una Circular, firmada por Ángel Pulido, en la que se afirma que la tuberculosis "no se hereda, sino en casos excepcionalísimos", pero "solamente en Madrid causa anualmente más de 2.000 víctimas, y en España pasan de 30 a 40.000" (Molero Mesa, 1987).

Se debe tener en cuenta que Manuel Martín Salazar fue un higienista importante en la Sanidad militar, pero también que durante el reinado de Alfonso XIII se convirtió en figura crucial en lo que concierne a la Sanidad española (Salas Fernández, 1998). En el citado discurso del médico sevillano sobre "La Sanidad en España" (1913), escrito un cuarto de siglo después de la monografía sobre la tuberculosis que estudiamos en este artículo (1887), encontramos que Martín Salazar señala, como otros muchos sanitaristas en España, el atraso de la administración y por tanto la necesidad de una regeneración sanitaria (Rodríguez Ocaña, 1994).

Recordemos, para terminar, algunos datos que corroboran la constante presencia e influencia del médico sevillano en la Sanidad militar y civil en España. En el curso 1898-1899 comenzó a impartir la asignatura de Higiene 
Militar en la Academia Médico-Militar, labor que llevó a cabo hasta 1907. En el seno del Ejército español fue comisionado en noviembre de 1901 para realizar el análisis bacteriológico de las aguas que abastecían la ciudad de Zaragoza y a partir de 1906, fecha que coincide con la del Premio Nobel otorgado a Santiago Ramón y Cajal, comenzó a dirigir la Revista de Sanidad Militar. En 1907 publicó su obra "Inmunidad con aplicación a la higiene y terapéutica de las enfermedades infecciosas", y siguió escribiendo sobre la tuberculosis en 1908 y en 1912, incluso en 1927 lo hizo en torno a la doctrina de Ferrán sobre esta enfermedad y su "vacuna antialfa" (Salas Fernández, 1998).

No olvidemos que en 1909 fue nombrado, dentro del contexto de la Sanidad civil, Inspector general de Sanidad Exterior, poniendo en marcha un Boletín de Estadística demográfico sanitario, y que en 1916 fue nombrado Inspector general de Sanidad del Reino, dimitiendo de la Dirección general de Sanidad en noviembre de 1923. Más de catorce años, pues, rigiendo los destinos de la Sanidad española; encontrándose en esos años con la mortífera epidemia gripal de 1918, preocupándose por la fiebre tifoidea, el tifus exantemático, el tracoma, la poliomielitis y, por supuesto, entre otras muchas enfermedades por la lucha antituberculosa. Asimismo, en el seno de la Real Academia Nacional de Medicina presidió la sección de Higiene.

Como hemos tenido ocasión de comprobar, Manuel Martín Salazar, estuvo destinado en Cádiz como médico militar en la década de los ochenta del siglo XIX. En este contexto, el médico de Montellano (Sevilla), publicó en Cádiz una extensa monografía de más de ochenta páginas que resume los avances científicos y médicos de la época, pero sobre todo la influencia del descubrimiento del bacilo de la tuberculosis (1882), hecho que consideraba determinante para plantear la "higiene de la tisis" partiendo de la doctrina parasitaria del médico alemán Robert Koch. Estando en Cádiz, pues, entabló relación con Benito Alcina Rancé, figura emergente en la década de los ochenta en la cátedra de Higiene Privada y Pública de la Facultad de Medicina, prologándole éste su monografía. Asimismo hemos tenido en cuenta en el análisis de la monografía de Martín Salazar, la tesis doctoral impresa en Cádiz y defendida en Madrid de Juan Luis Höhr Rodríguez (1888) (Herrera, 2009) y la monografía también impresa en Cádiz de Joaquín Portela González (1889) (B-FHR).

Nos ha llamado la atención, como ha quedado escrito en párrafos precedentes, que Benito Alcina, en esos años ochenta denunciaba la carencia de estadísticas sanitarias fiables en nuestro país, así como que la dirección de la Sanidad en España estuviera en manos de políticos que no entendían de los aspectos técnicos de la cuestión. Al cabo del tiempo, a partir de 1909 y hasta el año 1923, ese joven médico militar, llamado Martín Salazar, que le pidió un prólogo a Benito Alcina en 1887, fue una figura importante de la Sanidad en España. Pero encontramos otra vinculación de Martín Salazar con Cádiz: prologó, en 1917, al médico cántabro Leonardo Rodrigo Lavín (1867-1950), Inspector provincial de Sanidad, la "Monografía relativa al abastecimiento de aguas de Cádiz, San Fernando, Puerto Real y Puerto de Santa María”; pero este capítulo lo hemos estudiado en otro lugar, significando además que Rodrigo Lavín llegó a ser nombrado Subinspector General de Sanidad Interior en 1920, cuando todavía estaba al frente de la Sanidad española Manuel Martín Salazar (Herrera, 2007). Y, por último, otro hecho que lo vincula con Cádiz: la Junta de Gobierno de la 
Real Academia Hispano Americana de Ciencias y Artes de esta ciudad, lo admitió como Académico de Mérito en abril de 1923, siendo director de esta institución Pelayo Quintero (Salas Fernández, 1998).

Gregorio Marañón, en 1927, no dudó en calificar a Manuel Martín Salazar como "un epidemiólogo modernísimo, lleno de ideas y sugestiones; pero sedimentadas, distribuidas, cocidas en el horno de una mente toda claridad" (Salas Fernández, 1998). Palabras que en absoluto pueden ser consideradas excesivas si se analiza el conjunto de su obra como higienista e incluso esta temprana monografía escrita en Cádiz a la edad de 33 años, cuando todavía le quedaba mucho camino por recorrer.

\section{FUENTES Y BIBLIOGRAFÍA}

\section{Fuentes}

- Alcina Rancé, B. (1887). Prólogo En Martín de Salazar, Higiene de la tisis con arreglo a la nueva doctrina parasitoria (pp. 7-12). Cádiz: Imprenta y Litografía de la Revista Médica (Fondo antiguo de la Biblioteca de Ciencias de la Salud UCA, BCS-UCA).

- Expediente de doctorado de Juan Luis Höhr Rodríguez. Legajo 1482 (4)-Expediente $\mathrm{n}^{\circ} 53$ (Archivo Histórico Nacional. Madrid) (AHN).

- Expediente de Manuel Martín Salazar (Cuerpo de Sanidad Militar). Legajo M-1197 (Archivo General Militar de Segovia) (AGMS).

- Expediente de Manuel Martín Salazar. IDD (05)001.019, Caja 31/16157, expediente 934-64 (Archivo General de la Administración, Alcalá de Henares) (AGA).

- Höhr, J.L. (1888): Etiología y profilaxis de la tuberculosis. Memoria presentada en los ejercicios del doctorado. Imprenta de la Revista Médica, Cádiz (Biblioteca Facultad de Farmacia, Universidad Complutense de Madrid. Signatura: TD1888HOH) (BFF-UCM).

- Höhr, J.L. (1889). Prólogo. En J. Portela González, Reflexiones sobre la etiología y tratamiento antiséptico de la tuberculosis (pp. 3-6). Cádiz: Imprenta de la Revista Mé- dica de D. Federico Joly (Biblioteca Francisco Herrera Rodríguez) (B-FHR).

- Martín de Salazar, M. (1887). Higiene de la tisis con arreglo a la nueva doctrina parasitoria. Cádiz: Imprenta y Litografía de la Revista Médica (Fondo antiguo de la Biblioteca de Ciencias de la Salud UCA, BCS-UCA).

- Martín de Salazar, M. (1905). Estado sanitario del Ejército español. La Medicina Militar española y la Revistica de Clínica, Terapéutica y Farmacia, 217, 149-154 (Biblioteca Francisco Herrera Rodríguez) (B-FHR).

- Martín Salazar, M. (1913). La Sanidad en España. Madrid: Real Academia de Medicina (Biblioteca Facultad de Medicina, Universidad Complutense de Madrid. Signatura: Fo 989 (8) (BFM-UCM).

- Portela González, J. (1889). Reflexiones sobre la etiología y tratamiento antiséptico de la tuberculosis. Cádiz: Imprenta de la Revista Médica de D. Federico Joly (Biblioteca Francisco Herrera Rodríguez) (B-FHR).

\section{Bibliografía}

- Báguena Cervellera, M.J. (1991). La incidencia de la lucha antituberculosa en la mortalidad de la población valenciana (1882-1914). En J. Bernabeu Mestre (coord.), El papel de la mortalidad en la evolución de la población valenciana (pp. 193-199). Alicante: Instituto de Cultura Juan Gil Albert, Seminari d'Estudis sobre la Població valenciana.

- Báguena Cervellera, M.J. (1992). La tuberculosis y su historia. Barcelona: Fundación Uriach.

- Barona, J.L. (2007). José Chabás Bordehore (1877-1963). Tuberculosis y medicina social en la Valencia del primer tercio del siglo XX. Valencia: Consell Valencià de Cultura.

- Bartual Pastor, J., y Bartual Magro M. (1999). Apuntes para una historia de la Otorrinolaringología española (III). Los Portela y Cádiz. Anales de Otorrinolaringología, 2, 53-57.

- Bernabeu Mestre, J. (2007). Estadística y salud pública: el argumento del método numérico. Gaceta Sanitaria, 5, 416-417.

- Bernabeu Mestre, J. (2009). La higiene de la habitación. La arquitectura y salud pública en la España de la Restauración. Lars. Cultura y Ciudad, 15, 15-18. 
- Bernal-Borrego, E. (1994). Evaluación de la realidad sanitaria sevillana a través del análisis de la mortalidad durante el periodo de la Restauración (1875-1924). Actas del XXXIII Congreso Internacional de Historia de la Medicina (pp. 477-494). Sevilla: Sociedad Española de Historia de la Medicina.

- Carceller, A., y Lebel, M.H. (2005). Prevención de la tuberculosis en España en el siglo XXI. An Pediatr (Barc), 62 (3), 207-209.

- Carrillo, J.L. (1996). (coord.). Entre Sevilla y Madrid: estudios sobre Hauser y su entorno. Sevilla: Universidad de Sevilla.

- Carrillo, J.L. (1998). La salud de una ciudad: Sevilla ante la crisis finisecular. Dynamis, 18, 181-205.

- Casas de Ciria, I. (2012). Höhr, una familia alemana gaditanizada. La Vozdigital.es. Recuperado de http://www. lavozdigital.es/cadiz/20120129/cadiz/hohr-familia-alemana-gaditanizada-20120129.html. Consultado el 15 de agosto de 2016.

- Centro Nacional de Epidemiología Instituto de Salud Carlos III (2015). Informe epidemiológico sobre la situación de la tuberculosis en España. Año 2014. Madrid: Instituto de Salud Carlos III.

- Coury, Ch. (1972). Grandeur et déclin d'une maladie. La tuberculose au cours des ages. Suresnes: Lepetit S.A.

- Del Moral, C. (1979). Introducción. En Hauser, P. Madrid bajo el punto de vista médico-social (I, pp. 9-41). Madrid: Editora Nacional.

- Guillem-Llobat, X., y Perdiguero-Gil, E. (2014). Control de la calidad de los alimentos y urban penalty: a propósito del caso valenciano (1881-1915). Historia Social, 80, 113-131.

- Gutiérrez García, J.M. (2003). La tuberculosis bovina como zoonosis en la España contemporánea (18501950). Bellaterra. Recuperado de https://ddd.uab.cat/ pub/tesis/2003/tdx-0123104-155522/jmgg1de2.pdf Consultado el 15 de agosto de 2016

- Hauser, P. (1979). Madrid bajo el punto de vista médicosocial. Madrid: Editora Nacional.

- Hauser, P. (1990). Memorias autobiográficas (Introducción y notas: Juan L. Carrillo, Encarnación Bernal, Inés Bonilla). Sevilla: Secretariado de Publicaciones de la Universidad de Sevilla.
- Herrera Rodríguez, F. (1997). Crisis y medidas sanitarias en Cádiz (1898-1945). Zaragoza: Cuadernos de Historia de la Ciencia 10, Universidad de Zaragoza.

- Herrera Rodríguez, F. (1998). La obra médica de Benito Alcina Rancé (1853-1902). En J.L. García Hourcade et al (dirs.), Estudios de Historia de las Técnicas, la Arqueología y las Ciencias (VI Congreso de la Sociedad Española de Historia de las Ciencias y de las Técnicas) (pp. 859867). Salamanca: Junta de Castilla y León. Consejería de Educación y Cultura.

- Herrera Rodríguez, F (2002). Ángel Fernández-Caro y la tuberculosis en la Marina de Guerra (1907-1911). Medicina Marítima, 4, 223-227.

- Herrera Rodríguez, F. (2007). La obra sanitaria de Leonardo Rodrigo Lavín (1867-1950). Cádiz: Fundación Provincial de Cultura (Diputación de Cádiz).

- Herrera Rodríguez, F. (2009). El doctorado en la Facultad de Medicina de Cádiz en el siglo XIX. En Estudios superiores en Cádiz desde 1748. Armada e Ilustración (pp. 203-217). Cádiz: Ministerio de Defensa y Universidad de Cádiz.

- Herrera Rodríguez, F. (2012). John Keats, ¿cuyo nombre fue escrito en el agua? Gipuzkoa Médica, 70, 23-26.

- Huertas, R. (2002). Vivir y morir en Madrid: la vivienda como factor determinante del estado de salud de la población madrileña (1874-1923). Asclepio, LIV,2, 253-276.

- Laín Entralgo, P. (1998). Españoles de tres generaciones. Madrid: Real Academia de la Historia.

- Lederman, W. (2003). Franceses y alemanes tras la etiología de la tuberculosis. Rev. Chil. Infect., 43-45.

- López Piñero, J.M. (1984). M. Seoane. La introducción en España del sistema sanitario liberal (1791-1870). Madrid: Ministerio de Sanidad y Consumo.

- López Piñero, J.M. (1990). Historia de la Medicina. Madrid: Historia 16.

- Molero Mesa, J. (comp.) (1987). Estudios medicosociales sobre la tuberculosis en la España de la Restauración. Madrid: Ministerio de Sanidad y Consumo.

- Molero Mesa, J. (1989). La tuberculosis como enfermedad social en los estudios epidemiológicos españoles anteriores a la guerra civil. Dynamis, 9, 185-223.

- Molero Mesa, J. (1990). Francisco Moliner y Nicolás 
(1851-1915) y el inicio de la lucha antituberculosa en España. Asclepio. Revista de Historia de la Medicina y de la Ciencia, 1, 253-279.

- Orozco Acuaviva, A. (1981a). Bibliografía médico-científica gaditana. Cádiz: Obra cultural "Casino Gaditano”.

- Orozco Acuaviva, A. (1981b). La Gaceta de Higiene y Climatología 1880-1881 de Benito Alcina Rancé 18531902. Boletín Informativo del Excmo. Colegio Oficial de Médicos de Cádiz, 4, 16-18.

- Orozco Acuaviva, A. (1981c). La Crónica de especialidades médico-quirúrgicas 1884-1886 de Cayetano del Toro y Benito Alcina. Boletín Informativo del Excmo. Colegio Oficial de Médicos de Cádiz, 7, 5-9.

- Orozco Acuaviva, A., y Mira Gutiérrez, J. (1982). La enseñanza de la Higiene y la Microbiología en la escuela gaditana. En J. Mira y J.A. Zafra (coords.). Actas del VII congreso Nacional de Microbiología Cádiz, 1979 (pp. 308 y ss). Madrid.

- Porras Gallo, Mar.I. (1996). Evolución de la mortalidad de Madrid en el periodo 1883-1925. Una aproximación a la realidad sanitaria que conoció Philip Hauser. En J.L. Carrillo (coord.). Entre Sevilla y Madrid: estudios sobre Hauser y su entorno (pp.101-130). Sevilla.

- Rico-Avello, C. (1969). Historia de la Sanidad española (1900-1925). Madrid: E. Giménez, S.A.

- Rodríguez Aguado, O.O. (2015). La mortalidad en Cádiz (1900-1920). Tesis doctoral. Universidad de Cádiz. Recuperado en http://rodin.uca.es/xmlui/bitstream/handle/10498/18313/TESISDOCTORAL.pdf? sequence $=1$. Consultado el 12 de agosto de 2016.

- Rodríguez Ocaña, E. (1985). La labor estadística de Luis Comenge (1854-1916) en el Instituto de Higiene Urbana de Barcelona. Dynamis, 5/6, 279-306.

- Rodríguez Ocaña, E. (1988a) Los inicios de la estadística demográfico-sanitaria en Barcelona. La contribución de José Nin y Pullés (+1892). En M. Valera, M.A. Egea, y M.D. Blázquez (eds.). Libro de Actas. VIII Congreso Nacional de Historia de la Medicina (I, pp. 423-430). Murcia: Universidad de Murcia.

- Rodríguez Ocaña, E. (1988b). Presencia de la Estadística en los manuales españoles de Higiene Pública. En M. Valera, M.A Egea, y M.D. Blázquez, (eds.). Libro de Actas.
VIII Congreso Nacional de Historia de la Medicina (I, pp. 431-440). Murcia: Universidad de Murcia.

- Rodríguez Ocaña, E. (1993). Por la salud de las naciones. Higiene, microbiología y medicina social. Madrid: Ediciones Akal.

- Rodríguez Ocaña, E. (1994). La salud pública en España en el contexto europeo, 1890-1925. Revista de Sanidad e Higiene Pública, 68, 11-27.

- Rodríguez Ocaña, E. (1996a). La encuesta sanitaria como contribución original de Philipp Hauser a la salud pública española. En J.L. Carrillo (coord.). Entre Sevilla y Madrid: estudios sobre Hauser y su entorno (pp. 193-210). Sevilla: Imprenta A. Pinelo.

- Rodríguez Ocaña, E., y Bernabeu Mestre, J. (1996b). El legítimo criterio aritmético. Los métodos cuantitativos en la Salud Pública Española, 1800-1939. En E. SánchezCantalejo. (ed.). Quinto Encuentro Marcelino Pascua. La Epidemiología y la Estadística (pp. 9-33). Granada: Escuela Andaluza de Salud Pública

- Rosen, G. (1984). Análisis histórico del concepto de medicina social. En E. Lesky (dir.). Medicina social. Estudios y testimonios históricos (pp. 240 y ss.). Madrid: Ministerio de Sanidad y Consumo.

- Salas Fernández, M. (1998). Manuel Martín Salazar: apuntes biográficos. Sevilla: Excmo. Ayuntamiento de Montellano.

- Sosa, L.M., Cala, L.L. y Mantilla, J.C. (2007). Tuberculosis congénita asociada con tuberculosis materna miliar diseminada. Biomédica, 27, 475-482.

- Tamames, R. (1985). Una idea de España. Ayer, hoy y mañana. Barcelona: Plaza \& Janés Editores, S.A.

- Urkia Etxabe, J.M. (1992). La tuberculosis. Cuadernos de Sección. Ciencias Médicas, 2, pp. 139-153.

- Villanueva Edo, A. (1989). Historia social de la tuberculosis en Bizkaia (1882-1958). Bilbao: Diputación Foral de Bizkaia. 